\title{
LA IGUALDAD ANTE LAS CARGAS PÚBLICAS COMO CRITERIO PARA EVALUAR LA CONSTITUCIONALIDAD DE LIMITACIONES AL DERECHO DE PROPIEDAD
}

\author{
THE EQUALITY OF PUBLIC BURDENS AS A STANDARD FOR \\ EVALUATING THE CONSTITUTIONALITY OF REGULATIONS TO THE \\ RIGHT OF PROPERTY
}

\author{
Ignacio Covarrubias Cuevas ${ }^{*}$ \\ José Manuel Díaz de Valdés Julia*
}

\begin{abstract}
RESUMEN: A la luz de casos abordados por la Corte Suprema de EE.UU., el Tribunal Constitucional alemán y el Tribunal Europeo de DD.HH., este trabajo busca identificar criterios que pueden contribuir a evaluar la constitucionalidad de las normas legales que limiten el ejercicio del derecho de propiedad en virtud de estándares contenidos en la garantía constitucional de igualdad ante las cargas públicas, de modo que no respetar estos criterios de igualdad podría conducir a vulnerar el derecho de propiedad en su función social.
\end{abstract}

Palabras clave: derecho de propiedad, función social, igualdad ante las cargas públicas.

ABSTRACT: This paper attempts, drawing from the case law of the US Supreme Court, the German Constitutional Court and the European Court of Human Rights, to identify criteria for assessing the constitutionality of the legal rules affecting property, according to standards imposed by the constitutional right of equality of public burdens. Thus, ignoring these criteria may result in an infringement of property and its social function.

Keywords: right to property, social function, equality of public burdens.

\section{INTRODUCCIÓN}

Este trabajo intenta identificar elementos del principio de igualdad ante las cargas públicas que puedan ser pertinentes para evaluar la constitucionalidad de limitaciones, cargas u obligaciones ${ }^{1}$ impuestas al titular de un bien, normalmente invocando la función social del derecho de propiedad.

Lo anterior nace de constatar que la discusión sobre limitaciones a la propiedad gira casi exclusivamente sobre el estatuto de este derecho ${ }^{2}$. Se echa en falta incorporar al análisis

\footnotetext{
Doctor en Derecho por la Universidad de los Andes. Actualmente es Decano y profesor de derecho constitucional de la Facultad de Derecho de la Universidad Finis Terrae. Código Orcid: 0000-0002-3369-7284, Dirección postal: Av. San Ramón Sur 2910-3, Santiago, Chile. Dirección electrónica: icovarrubias@uft.cl.

** Doctor en Derecho por la Universidad de Oxford. Actualmente es Director del Centro de Justicia Constitucional de la Universidad del Desarrollo. Código Orcid: 0000-0002-1258-0319. Dirección postal: Av. Santa María 6270 depto. 912, Santiago, Chile. Dirección electrónica: jdiazdevaldes@udd.cl.

1 Usaremos indistintamente las expresiones "restricciones, obligaciones, cargas y regulaciones" como sinónimos de "limitaciones" impuestas al ejercicio del derecho.

2 Aldunate (2006); Cordero (2006); Zúñiga (2013) pp. 145 y ss.
} 
ciertas garantías o doctrinas, tales como la igualdad ante las cargas públicas, el contenido esencial del derecho ${ }^{3}$, o la proporcionalidad, para discernir casos de regulaciones inconstitucionales a la propiedad ${ }^{4}$.

Así, algunos autores han señalado que un acto que afecta excesivamente la propiedad, sin prever la correspondiente indemnización, podría incurrir en inconstitucionalidad por lesión a la igualdad ante las cargas públicas 5 . La inconstitucionalidad y la eventual reparación pecuniaria, constituirían el modo de restablecer la igualdad ante las cargas públicas quebrantada, dado el sacrificio que para el titular del derecho importa una norma que busca beneficiar a la comunidad toda ${ }^{6}$. Otros autores coinciden en atribuir a la igualdad ante las cargas públicas un rol clave, pero para controlar si una norma legal ha cumplido con el equilibrio que la función social de la propiedad lleva consigo.

Nuestro trabajo pretende continuar estas líneas doctrinales, recogiendo elementos del derecho comparado que pueden ser útiles para esta discusión. Adicionalmente, sin pretender ser un trabajo de doctrina y jurisprudencia nacional ${ }^{7}$, su referencia será indispensable para exhibir el aporte que contienen las sentencias del Tribunal Constitucional Alemán, de la Corte Suprema de los Estados Unidos y del Tribunal Europeo de Derecho Humanos ${ }^{8}$, para perfilar los criterios de la igualdad ante las cargas públicas como parámetros para discernir la constitucionalidad de las regulaciones al derecho de propiedad.

\section{LA FUNCIÓN SOCIAL IMPLICA UN EQUILIBRIO ENTRE DUEÑO Y SOCIEDAD}

Desde Galletué, algunas sentencias de nuestros tribunales han señalado que ciertas limitaciones al derecho de propiedad, aunque "loables" en cuanto a su finalidad, no podían se soportadas "por algunos ciudadanos, alterando con ello el principio de la igualdad en la repartición de dichas cargas".

Más recientemente en Chile, en Constructora Santa Beatriz con Monumentos Nacionales $(2014)^{10}$, el Tribunal Constitucional (TC) recordó que las limitaciones al derecho

\footnotetext{
3 Fermandois (2006); Delaveau (2006) p. 413; Aldunate (2006) p. 296; Matute (2014) p. 205.

4 Fermandois (2006); Marmolejo (2008), García (2011) p. 101; Bronfman (2012) p. 250.

5 Aldunate (2006) pp. 296 y 298. Ponce de León (2014) p. 450; Quezada (2018) p. 113.

${ }^{6}$ Aldunate (2006) p. 301; Ponce de León (2015) p. 864: la carga pública opera como fundamento de exigencia de equilibrio a favor de quien soporta el gravamen en pos de la comunidad. Véase también RAJEVIC (1996) p. 46 y Guiloff (2018) pp. 280 y ss.

7 Creemos que la igualdad ante las cargas públicas, del artículo 19 № 20, es una iteración específica de la garantía general de igualdad en y ante la ley, del artículo 19 No 2. Por tanto, lo dicho para esta última, extensamente tratada por la doctrina y la jurisprudencia nacional, aplica a la igualdad ante las cargas.

${ }^{8}$ Coincidimos con López Escarcena (2015) p. 44, quien afirma que en la mayoría de las sentencias en que la Corte Interamericana de DD.HH. aborda el derecho de propiedad individual, lo ha hecho "únicamente después de haber encontrado violaciones a otras disposiciones de su tratado constitutivo, y en gran medida como consecuencia de dichos incumplimientos" y además "sigue normalmente los criterios de la Corte Europea de Derechos Humanos", motivo por el cual no se previó abordar la jurisprudencia de la Corte Interamericana dentro de resultados comprometidos para este Proyecto de Investigación.

9 Quintana Olivares y otros con Fisco (2000).

10 REQUERIMIENTO DE INAPLICABILIDAD, LEY 17.288, Rol 2299-12 (2014) c. $7^{\circ}$ y $8^{\circ}$.
} 
de propiedad, fundadas en la función social, debían respetar el adecuado equilibrio entre aquél y otros derechos o principios que puedan verse comprometidos, como la igualdad y el principio de proporcionalidad. El TC ha destacado, también, que la carga debe ser evaluada según "las limitaciones que puedan sufrir otros propietarios que se encuentren en la misma situación en atención a la entidad o naturaleza de la razón involucrada en el ejercicio de la función social de la propiedad.”. Agregó que las cargas deben "ser repartidas entre todos los llamados a soportarlas, de manera igualitaria y equitativa. Por lo que la igualdad ante las cargas públicas [...] es, pues, una aplicación del principio general de isonomía o de igualdad ante la ley"11.

Tal y como ha señalado el TC en diversas ocasiones, la función social es inherente el dominio $^{12}$, se traduce en "deberes y responsabilidades que buscan armonizar los intereses del dueño con los de la sociedad", y no se estimaría como un daño indemnizable, debiendo el titular del derecho soportarla en pos del bien común ${ }^{13}$.

Estas nociones se corroborarían en otra sentencia del TC, al estimar la constitucionalidad de una carga pública impuesta a una empresa inmobiliaria de ceder gratuitamente una porción de sus terrenos para fines de urbanización. Dicha cesión gratuita, dice el TC, es un modo "de conciliar en forma prudente y justa los intereses personales del urbanizador con los de la sociedad toda, arbitrando los medios necesarios para que el Estado cumpla su fin primordial, cual es el bien común"14.

Similarmente, en otro caso declaró que el carácter gratuito de las servidumbres mineras concretizan un ejemplo de restricción, no de privación, a la propiedad minera, por lo que la obligación impuesta "no sería indemnizable" 15 , sin perjuicio que, en este caso existiera indemnización en virtud de disposición legislativa expresa" ${ }^{16}$.

Destacamos dos conclusiones extraíbles de estos fallos. Primero, que la función social supone una relación armonizadora entre el derecho de propiedad y las exigencias impuestas en su nombre, se forma de "balancear los legítimos intereses públicos con la defensa de la propiedad privada”, conforme a la Constitución ${ }^{17}$. Segundo, que hay una exi-

\footnotetext{
11 Requerimiento de inaplicabilidad, LEY 18.549, Rol 790-07 (2007) c. $38^{\circ}$ y REQUeRIMIENTO DE INAPLICABILIDAD, LEY 17.288, ROL 2299-12 (2014) c. 11\%.

12 Véase Requerimiento de Diputados y Senadores, Decreto Supremo No 1 DE 1996 del Ministerio de Bienes Nacionales, Rol 245-96 (1996) y Requerimiento de Diputados y Senadores, Decreto Supremo No 1 de 1996

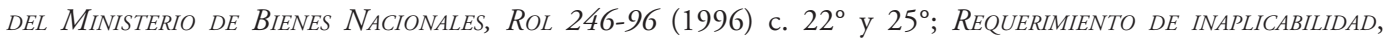
DECRETO CON FUERZA DE LEY 850, ROL 1991-11 (2012) c. 42²; REQUERIMIENTO DE INAPLICABILIDAD, DECRETO CON FUERZA DE LEY 850, ROL 1993-11 (2012) c. $42^{\circ}$ y REQUERIMIENTO DE INAPLICABILIDAD, LEY 17.288, ROL 2299-12 (2014) c. $7^{\circ}$.

13 REQUERIMIENTO DE INAPLICABILIDAD, LEY 17.288, ROL 2299-12 (2014) c. $8^{\circ}$.

14 Requerimiento de Senadores, Decreto Supremo No 171 de 1996 del Ministerio de ViVIenda y URBanismo, ROL 253-97 (1997) c. $10^{\circ}$.

15 REQUERIMIENTO DE INAPLICABILIDAD, LEY 18.097, ROL 1284-08 (2009) c. 21\%.

16 REQUERIMIENTO DE INAPLICABILIDAD, LEY 18.097, ROL 1284-08 (2009) c. 21\%.

17 REQUERIMIENTO DE INAPLICABILIDAD, LEY 19.949, ROL 505-06 (2007) y REQUERIMIENTO DE INAPLICABILIDAD, LEY 19.949, ROL 506-06 (2007) c. $17^{\circ}$ a $1^{\circ}$. Asimismo REQUERIMIENTO DE INAPLICABILIDAD, ART. 309 DEL COD. DE AGUAS, ROL 1309-09 (2010) c. 20 y $4^{\circ}$ y REQUERIMIENTO DE INAPLICABILIDAD, DECRETO CON FUERZA DE LEY 850, Rol 1993-11 (2012), REQUERIMIENTO DE INAPLICABILIDAD, DECRETO CON FUERZA DE LEY 850, ROL 2043-11 (2012), REQUERIMIENTO DE INAPLICABILIDAD, DECRETO CON FuERZA DE LEY 850, Rol 2077-11 (2012), REQUERIMIENTO DE
} 
gencia constitucional de que las limitaciones a la propiedad en virtud de su función social sean repartidas de manera igualitaria entre quienes se encuentran en la misma situación en atención a la naturaleza de la razón invocada por la legislación.

\section{EQUILIBRIO ENTRE EL BIEN COMÚN Y LOS INTERESES DEL DUEÑO EN DERECHO COMPARADO}

\subsection{Tribunal Europeo de Derechos Humanos}

El justo equilibrio entre los intereses de la comunidad y los de la persona afectada es uno de los criterios fundamentales que emplea el Tribunal Europeo de Derecho Humanos (TEDH) para decidir si una norma que incide en el derecho de propiedad se encuentra o no justificada ${ }^{18}$. El justo equilibrio opera si la norma es legal y no es arbitraria ${ }^{19}$, y se rompe si el acto implica una carga excesiva al afectado ${ }^{20}$, por muy importante que sea el fin, debiendo haber una proporcionalidad entre este y los medios previstos para lograrlo. Si bien se admite un amplio margen de apreciación a los Estados en elegir los fines y medios en materia de políticas económico-sociales que puedan afectar la propiedad ${ }^{21}$, esta deferencia no inmuniza el control sobre si el acto cumple el justo equilibrio. Además, el justo equilibrio no sirve para decidir si hay una privación, una regulación al uso de la propiedad u otro tipo de interferencia, sino que debe cumplirse cualquiera sea el modo de afectación ${ }^{22}$.

Forminster (2008) delineó ciertos factores para evaluar si el acto impone una carga excesiva: "la intensidad de la interferencia, el fin perseguido, la naturaleza de los derechos de propiedad afectados, y la conducta del reclamante como de las autoridades del Estado"23. La intensidad de la interferencia varía dependiendo de si existe una privación, una regulación al uso u otra injerencia. Si hay privación, los términos de la compensación "son cruciales para discernir si la normativa objetada respeta el justo equilibrio de los intereses en juego y, notoriamente, si ella no impone una carga desproporcionada" ${ }^{24}$. Hay derecho a una adecuada y pronta compensación ${ }^{25}$, entendiéndose que ha de ser completa y según el valor de mercado del bien privado ${ }^{26}$. Una compensación así es el modo de cumplir el justo equilibrio si hay una privación -directa o indirecta (de facto) a la propiedad ${ }^{27}$. Si no hay privación, no hay de-

INAPLICABILIDAD, DECRETO CON FUERZA DE LEY 850, ROL 2078-11 (2012), REQUERIMIENTO DE INAPLICABILIDAD, DECRETO CON FUERZA DE LEY 850, ROL 2079-11 (2012) c. 44․

18 Sporrong y LönNRoth Vs. Suecia (1982) párr. 69; Monasteries vs. GreCIA (1994) párr. 70; Allen (2007) pp. 294-298 y LÓPEZ (2014) pp. 60-61.

19 SERYAVIN Y OtROS VS. UKRANIA (2011) párr. 107; BEYELER VS. ITALY (2000) párr. 107.

20 Montt (2009) p. 220. El autor estima que el fair balance no aplica en caso de privaciones.

21 Sobre el margen de apreciación: Arai-TaKaHASHI (2002), García Roca (2010), LegG (2012).

22 Sporrong y LÖNNROTH VS. SuECIA (1982) párr. 69; MoNASTERIES VS. GRECIA (1994) párr. 70.

23 Forminster ENTERPRISES Limited VS. CZECH REPUbLIC (2008) párr. 77.

24 James Vs. REINO UNIDO (1986) párr. 54; PERDigÃo VS. PORTUGAL (2010) párr. 68.

25 TRE TRAKTÖRER AKTIEBOLAG VS. SWEDEN (1989).

26 Turgut and others vs. Turquí (2008) y Althoff and others VS. Alemania (2011). Véase Sluysmans, Verbist y De Graaf (2014) pp. 3-33.

27 Solo en los denominados "casos de transición", el TEDH ha admitido una salvedad al deber de compensar si hay una privación. Véase Sluysmans, Bosma, Timmer y Van Triet (2015) pp. 379-399. 
ber de compensar por el valor total, aunque los términos de la compensación son relevantes para determinar si se ha cumplido o no con el justo equilibrio.

Otro factor, el fin perseguido, se vincula a la proporcionalidad de la compensación. Afirma que si bien no se "garantiza a todo evento el derecho a una compensación total, el Tribunal estima que [...] hay una ligazón directa entre la relevancia o naturaleza preponderante del interés público y la compensación que ha de ser prevista [...] Una escala decreciente debería ser aplicada al respecto, equilibrando el alcance y grado de importancia del interés público con la naturaleza y monto de la compensación prevista para las personas involucradas" 28 .

Sobre la base de estos criterios, existe una interesante jurisprudencia posterior del TEDH. En Immobiliare (1999), declaró que una ley que autorizó suspender por años la ejecución de desalojos supuso una carga excesiva para el propietario que, habiendo obtenido una orden de desalojo, no pudo ejecutarla ${ }^{29}$. En Chassagnou (1999), dijo que el acto que restringió el uso de pequeños propietarios fue excesivo al haber una diferencia de trato entre estos y otros propietarios ${ }^{30}$. En Hutten-Czapsk (2006), la limitación a la facultad de los dueños de ciertos inmuebles para aumentar la renta de arriendo o para ponerle fin, no logró el justo equilibrio, pues la "carga no puede, en este caso, ser soportada por un grupo social en particular, no obstante, lo relevante que sean los intereses del otro grupo o de la comunidad en su conjunto" ${ }^{31}$.

En Saliba (2011), se afirmó que el motivo que durante la posguerra había legitimado que el Gobierno ocupara forzosamente bienes raíces de terceros, ya no se justificaba, pues la norma primitiva hacía que actualmente los afectados "soportaran la mayor parte de los costos sociales y financieros del suministro de viviendas"32. En Lindheim (2012), se puso en duda que los fines sociales de una ley justificaran actualmente las restricciones al arriendo de viviendas, en beneficio de los arrendatarios, pues ello no produjo "una distribución equitativa de la carga social y financiera, sino más bien que la carga recayó exclusivamente en los arrendadores"33. Hay otros casos en que se estimó que el Estado no había logrado el justo equilibrio, sea porque desconoció el pago de un beneficio social otorgado por sentencia judicial ${ }^{34}$, sea porque no se respetó el contenido esencial del derecho ${ }^{35} \mathrm{o}$, por el atraso del pago de la pensión, que, unido a la alta inflación, agudizó el desequilibrio por la desvalorización del beneficio ${ }^{36}$.

Respecto de injerencias que no sean privaciones, también pueden identificarse criterios para evaluar si se cumple el justo equilibrio: la ley estatal puede ser desproporcionada si impone una carga cuyo fin ya no es tan relevante como el primitivamente concebido.

28 URBARSKA OBEC TRENČIANSKE BISKUPICE VS. ESLOVAQUIA (2007) párr. 115.

29 INMOBILIARIA SAFFI VS. ITALIA (1999) párr. 74.

30 CHASSAGNOU VS. FRANCIA (1999) párr. 92.

31 Hutten-CZapsk vs. Polonia (2006) párr. 225.

32 SALIBA AND OTHERS VS. MALTA (2011) párr. 67.

33 LiNDHEIM AND OtHeRS VS. NORUEGA (2012) párr. 134.

34 Pravednaya vs. Rusia (2004) párr. 40-41. Véase Barcelona Llop (2017) pp. 334-335.

35 DRUZSTEVNi ZALAZNA PRIA AND OtHERS VS. REPÚBLICA CHECA (2008) párr. 93.

36 SolodyuK vs. Rusia (2005) párr. 28 y ss. Véase Gómez Heredero (2007) pp. 30-31. 
Similarmente, podría serlo al extenderse el carácter transitorio de una carga. Ésta también podría tornarse excesiva si es soportada por un grupo de personas que se encuentran en situación de compartir con otros semejantes dicho gravamen, o si la carga perjudica a una persona aisladamente considerada. Estos criterios también han sido aplicados por el TEDH frente a actos que han suspendido o recortado beneficios sociales legítimamente adquiridos.

\subsection{Tribunal Constitucional alemán (TCA)}

El TCA ha afirmado, como principio, que respecto de la función social del derecho de propiedad "el legislador debe lograr un justo equilibrio y una relación equitativa entre los legítimos intereses de las partes involucradas" ${ }^{37}$, lo que "se cumple si las obligaciones que emanan del derecho de propiedad son consistentemente razonables [...] tales regulaciones no pueden dar lugar a una carga excesiva que afecte irrazonablemente los derechos del propietario" 38 . En regulaciones a la propiedad, añade, "el principio de igualdad ante la ley debe ser respetado como principio del Estado de Derecho" 39 .

Así, en Ley de Pequeños Huertos (1979), se declaró inconstitucional una norma que restringía el derecho de poner fin anticipado a contratos de arriendo. La ley se dictó en una época en que era habitual que los dueños de grandes terrenos arrendaran pequeños lotes como huertos, cuya explotación fue clave para promover la provisión más barata de alimentos, tanto para los arrendatarios como para Alemania. Con el advenimiento de la producción alimentaria masiva y el crecimiento de las ciudades, los arrendadores prefirieron dar a sus tierras un uso más intensivo para fines comerciales, pues la renta era mucho mayor que para el uso agrícola.

El regulador rechazó una solicitud de los dueños de los lotes para terminar anticipadamente los arriendos, pues la ley no preveía el cambio de circunstancias como fundamento para poner fin al contrato. Llevado el asunto ante el TCA, la declaró inconstitucional ya que la magnitud de la restricción a la libertad de los dueños era actualmente desproporcionada respecto del fin público primitivamente perseguido, esto es, que los huertos fueran fuente de alimentación en tiempos de necesidad, y ahora tales lotes no cumplían sino una función recreativa de relevancia social, menos poderosa que la función originalmente concebida $^{40}$. Así, la inconstitucionalidad emanaba de no cumplir un estándar mínimo de razonabilidad: la restricción prevista originariamente ya no cumplía su cometido ${ }^{41}$.

En Cesión de Ejemplares (1981), se estimó inconstitucional la carga impuesta a todos los editores de libros, de ceder gratuitamente a la biblioteca pública un ejemplar de cada edición para que los nuevos textos estén al alcance de todos y se garantice su conservación. Un editor de libros de lujo reclamó que la norma le ocasionaba un perjuicio, dadas las características de su negocio. El TCA afirmó que, si bien la ley era una delimitación a la propiedad, no una expropiación, no se ajustaba al principio de proporcionalidad y de

37 Cesión de Ejemplares (1981) BVerfGE 58, 137, en BröHMER (2012) p. 692.

38 Cesión de Ejemplares (1981) BVerfGE 58, 137, en BröHMER (2012) p. 692.

39 Cesión de Ejemplares (1981) BVerfGE 58, 137, en BRÖHMER (2012) p. 692.

40 Pequeños Huertos (1979) BVerfGE 52, 1, en Schwabe (2009) pp. 412-413.

41 Alexander (2006) p. 136. 
igualdad, al gravar por igual a todos quienes se dedican a la actividad editorial sin reparar que la carga era desproporcionada y discriminatoria para el editor a quien le era imposible cumplir con la obligación, pues editaba colecciones de lujo con un reducido tiraje de venta.

Junto con admitirse que la norma buscaba un fin legítimo y que ceder gratuitamente copias de cada edición era en principio razonable, dijo que la "deficiencia" observada aquí "representa una carga significativa en comparación con los editores a bajo costo y a gran escala" por lo que su situación "no puede ser considerada aisladamente de las características de su producción" ${ }^{2}$. Se infringía así la igualdad ante la ley, la que exigía "en este caso que los elementos de la regulación [...] se encuentren ordenados de modo tal que las diferencias generadas en la carga impuesta a los dueños y que las diferencias en el peso de sus intereses en comparación con los intereses del público, sean tomadas en consideración con las necesarias distinciones, evitando una carga desigual”³.

En Monumentos Nacionales (1999), el TCA señaló que la norma que buscaba proteger el patrimonio histórico de ciertos inmuebles, produjo un "vaciamiento material de las facultades del dominio y la exclusión de cualquier posibilidad de aprovechamiento", estimándola inconstitucional al imponer carga desproporcionada infractora de la igualdad. Una regulación a la propiedad puede ser inconstitucional, no solo por ser expropiatoria ${ }^{44}$, sino por verificarse una "restricción injustificada" 45 al derecho. La norma en cuestión invocaba el interés público histórico y cultural en conservar ciertas propiedades. Su artículo 13 disponía que solo por motivos de bien común, y sin considerar el interés privado, podía autorizarse la alteración del bien raíz protegido. Como el dueño no había encontrado compradores y la propiedad estaba vacía desde 1981, solicitó autorización para demolerla, dado el costo altísimo de mantención y que le estaba prohibido usarla para fines distintos al residencial. La solicitud le fue denegada, fundada en que, bajo esta ley, la autoridad solo debía considerar el interés público en demoler y no el interés del dueño.

El fallo parte por afirmar que, al regular el contenido y límites del derecho de propiedad, la ley "debe lograr un justo equilibrio y una equitativa relación entre el legítimo interés del dueño y las necesidades del bien público. Al hacerlo, el legislador debe ser consistente con todas las otras [...] garantías constitucionales; en especial, debe sujetarse al principio constitucional de proporcionalidad y al principio de igualdad ante la ley". Añade que las "limitaciones al derecho no pueden exceder aquello que sea suficiente para lograr el propósito buscado por la regulación legal. No lo está permitido vaciar el aspecto nuclear del derecho de propiedad" 46 .

La inconstitucionalidad de la norma no reside en el fin ni en el deber del dueño de suportar la carga de conservar el inmueble declarado monumento, pues "[l]a prohibición de demoler el monumento arquitectónico no restringe su uso habitual" y "la Ley Funda-

42 Cesión de Ejemplares (1981) BVerfGE 58, 137, en BrÖHmer (2012) pp. 693-694.

43 Cesión de Ejemplares (1981) BVerfGE 58, 137, en BröHmer (2012) p. 694.

44 Para el TC alemán una ley es expropiatoria solo si persigue formalmente una expropiación.

45 AdVERTENCIA DE GLICOL EN LOS VINOS (2002).

46 Monumentos Nacionales (1999) BVerfGE 100, 226, en BRÖHMER y otros (2012) p. 698. 
mental no protege el uso más rentable de la propiedad" ${ }^{47}$. Cosa distinta ocurre "cuando ya no es posible un uso significativo del monumento arquitectónico protegido". Si el dueño "no puede darle un uso razonable", ni "disponer del mismo por motivos prácticos, la posibilidad de un usufructo privado por el dueño se encuentra virtualmente excluido del todo. Si se añade el deber legal de conservar la propiedad, el derecho se transforma en una carga que el dueño tendrá que soportar con fundamento en el interés general, sin poder gozar de las ventajas del uso privado. La posición jurídica del afectado se parece a una situación en que no merece denominarse 'propiedad"'48. Así, garantizar el aprovechamiento privado es un límite absoluto a la regulación de la propiedad ${ }^{49}$.

La compensación prevista en la ley tampoco impidió la inconstitucionalidad, pues "las normas que establecen compensaciones no son generalmente un modo aceptable de asegurar la consistencia de limitaciones no razonables al derecho de propiedad. Las normas que definen el contenido y los límites de la propiedad deben en principio preservar la sustancia de los derechos de propiedad, aunque haya compensación, y cumplir con el principio de igualdad ante la ley" 50 .

\subsection{Corte Suprema de EE.UU.}

No es fácil identificar estándares uniformes en las decisiones de este tribunal, acerca de si una norma que interfiere con el derecho de propiedad constituye o no una expropiación regulatoria. Con todo, es posible detectar ciertos criterios en materia de igualdad ante las cargas públicas, que han contribuido a evaluar la constitucionalidad de las regulaciones a la propiedad. Así, desde 1922, este tribunal ha sido estable en afirmar que la enmienda que establece que la propiedad "no será quitada [taken] para el uso público sin una justa compensación", opera como una garantía que busca que las potestades regulatorias no vayan "demasiado lejos" al establecer normas al uso del derecho. Si bien la determinación de criterios para esto ha sido confusa ${ }^{51}$, la Corte ha sido uniforme en reiterar uno de ellos -de igualdadsegún el cual evaluar la constitucionalidad de una norma que afecta la propiedad.

Desde Pennsylvania Coal (1922) se afirma que la cláusula constitucional de propiedad sirve para limitar el poder estatal de imponer restricciones al derecho. Se han identificado ciertos factores para decidir si la norma iba "demasiado lejos" y debía ser expropiatoria. Un punto es la idea de balanceo entre el interés público y el derecho de propiedad, esto es, la idea de equilibrio entre la regulación y el efecto en la propiedad ${ }^{52}$. Se estableció entonces que un factor crucial para evaluar la constitucionalidad de dicho equilibrio exi-

\footnotetext{
47 Monumentos Nacionales (1999) BVerfGE 100, 226, en BRÖHMER y otros (2012) p. 699.

48 Monumentos Nacionales (1999) BVerfGE 100, 226, en BrÖHMER y otros (2012) p. 699.

49 Lubens (2007) p. 417.

50 Monumentos Nacionales (1999) BVerfGE 100, 226, en BRÖHMER y otros (2012) p. 700.

51 Si bien subrayaremos aquellos aspectos favorable a nuestra hipótesis en las decisiones de la Corte Suprema norteamericana, cabe advertir que hay una extensa doctrina crítica de distinta intensidad sobre criterios utilizados por dicho tribunal en materia de regulaciones expropiatorias. A modo ejemplar, cabe señalar RosE (1984); Rose-Ackerman (1988); Wenar (1997); Merrill (2000); Doremus (2003), entre otros.

52 Gaba (2007) p. 574.
} 
ge que "en la acción estatal [concurra] una equitativa distribución de beneficios y cargas, como es característico en las leyes de zonificación y en la legislación de sitios históricos" 53

Esta idea de Pennsilvania Coal fue retomada en varios casos. En Armstrong (1960) se dijo que la prohibición de establecer privaciones (takings) a la propiedad sin una justa compensación "fue diseñada para impedir que el Estado imponga a algunos a llevar solos las cargas públicas que, en equidad y justicia, deberían ser llevadas por el público como un todo" 54 . Esta fórmula fue reiterada en la mayoría como en la disidencia de Penn Central (1978), un caso clave sobre la constitucionalidad de la ley de monumentos históricos, que impedía a los propietarios de la estación Penn introducir cambios mayores al edificio declarado monumento histórico.

Afirmó que la carga era una ventaja para la ciudad como para los dueños, pues "la preservación de monumentos beneficia a los ciudadanos de Nueva York como a sus construcciones, tanto económicamente como por la mejora de la calidad de vida de la ciudad" 55 . El disidente afirmó que los dueños habían sido injustamente tratados al hacerles cargar individualmente el costo de un beneficio público. El punto "es si el costo derivado del fin [...] de preservar un número de monumentos históricos [...] debe ser soportado por todos los contribuyentes o puede recaer totalmente en los propietarios individuales" Esta ley, dijo, era distinta a la mayoría de las normas de zonificación, que se justifican por el hecho que, en un área delimitada, todos los propietarios están sujetos a las mismas restricciones, pero no únicamente en beneficio de la municipalidad, sino en aras del beneficio compartido de cada uno ${ }^{57}$. Tal mutua reciprocidad no existe, concluyó, cuando "edificios singulares [...] son excluidos y tratados de modo diferente que el resto de los edificios"

Interesante es observar que el asunto de "reciprocidad en las ventajas" como factor relevante para evaluar si el balance previsto por la norma es constitucional, fue invocado por la mayoría y por el disidente. Esta interpretación contrapuesta sobre su aplicación se debe probablemente al carácter prudencial que supone apreciar el equilibrio o proporcionalidad entre lo que la norma quita por un lado y lo que da o mantiene por otro. Así, "[a]unque una regulación puede imponerme una carga para beneficiar a otro, la misma regulación puede beneficiarme. La reciprocidad, examina en parte, la magnitud de la pérdida" ${ }^{9}$.

Así, el factor de reciprocidad en las ventajas puede conducir a otro factor que ha considerado el tribunal en la regulación a la propiedad: la "magnitud de la pérdida". La reciprocidad busca evaluar si la carga impuesta se ve compensada con el beneficio que la misma norma establece ${ }^{60}$, por lo que, si existe un aporte al bien común y la carga impuesta es mínima, difícilmente puede decirse que el dueño ha sido desproporcionadamente afectado por la regulación. En tal caso, podría no ser necesario acudir a la "magnitud de la pérdida":

\footnotetext{
53 Pennsylvania Coal Co. v. Mahon (1922).

54 Armstrong V. United States (1960).

55 Penn Central Transportation Co. v. NeW York City (1978).

56 PenN Central Transportation Co. v. NeW York City (1978).

57 Penn Central TRansportation Co. v. NeW York City (1978).

58 PenN Central TRANSPortation Co. v. NEW York City (1978).

59 GABA (2007) p. 585.

${ }^{60}$ GABA (2007) p. 585.
} 
al no haber pérdida o al ser mínima, se entiende que debería ser tolerada en pos de un bien común que beneficia incluso - directa o indirectamente- al mismo propietario que soporta el costo de la norma.

En materia de regulación urbanística, uno de los elementos considerados para determinar la magnitud de la pérdida ha sido el porcentaje de disminución del valor del bien raíz, pero no hay un criterio que permita delinear si la pérdida es de tal magnitud como para considerarla inconstitucional si no se ha previsto una compensación. Los casos suelen abordarse mediante una ponderación entre el interés público y el del propietario, por lo que son escasas las hipótesis de regulaciones inconstitucionales per se. Una, es la disminución de un $100 \%$ del valor de la propiedad ${ }^{61}$. Otra, es la invasión física permanente, no autorizada por el dueño, en su propiedad ${ }^{62}$.

Si bien en Lucas (1992) el impacto de la norma fue clave (la pérdida total de valor), según algunos el caso no se entiende del todo sin el siguiente aspecto: una carga desigual no justificada ${ }^{63}$. El reclamante fue afectado por una ley, sobreviniente a la compra de su terreno, que le impidió construir, esto es, hacer aquello que los vecinos que estaban en una situación similar habían hecho ${ }^{64}$. Por ello, las expectativas del propietario aquí eran más fuertes que las del dueño en el caso Penn. Un enfoque que se esgrime en limitaciones a la propiedad es la justificación de imponer una carga no compensada, que genera el efecto de impedir al dueño hacer lo que la mayoría de los dueños vecinos habían hecho lícitamente ${ }^{65}$. Michelman echa en menos un mayor control judicial aquí y dice que un punto clave para evaluar si la lesión causada por una norma a la propiedad es inconstitucional exige comparar el carácter de la lesión con la afectación de otros que estarían en una situación similar ${ }^{66}$.

Más allá de las controversias que la igualdad suscita en estas materias ${ }^{67}$, su influencia es indudable ${ }^{68}$. Ello se debe a que el control jurídico de las regulaciones a la propiedad siempre lleva consigo la posibilidad de evaluar la igualdad en la distribución de cargas y beneficios. De hecho, el influyente caso Lingle v. Chevron (2005) delineó los dos elementos claves que debe incorporar cualquier revisión judicial de la propiedad: "la magnitud o carácter que impone la carga de una regulación específica sobre los derechos de propiedad" y "cómo una carga regulatoria es distribuida entre los dueños de la propiedad" 69 . En fin, aunque la doctrina jurisprudencial sobre regulaciones expropiatorias "es ampliamente vista como una defensa del individuo contra actos estatales excesivos y arbitrarios", también "puede ser vista como un resguardo del derecho a la igualdad frente al Estado" 70.

61 Lucas v. South Carolina Coastal Council (1992).

62 Loretto V. Telepromter Manhattan CATV Corp. (1982).

63 Singer (2015) pp. 653-654.

64 Lucas v. South Carolina Coastal Council (1992).

65 Singer (2015) p. 654.

66 Michelman (2012) pp. 221-222.

67 Hanoch (1999) pp. 778-792, Fee (2004) pp. 1049-1060, Gaba (2007) pp. 576-583.

68 Dana y Merrill (2002) pp. 33-34.

69 LiNGLE V. CHEVRON U.S.A. INC. (2005).

70 FeE (2004) pp. 1004 y 1007. 


\section{LA IGUALDAD CONSTITUCIONAL COMO LÍMITE A LAS CARGAS PÚBLICAS}

Entre las concepciones de igualdad constitucional que conviven en la actualidad ${ }^{71}$, veremos que dos de ellas podrían proveer criterios para fundar la igualdad ante las cargas públicas.

\subsection{Igualdad ARistotélica}

La igualdad constitucional se funda en la noción aristotélica de tratar igual a los iguales y desigual a los iguales ${ }^{72}$. Un rasgo de esta igualdad es su "autonomía": permite juzgar la constitucionalidad de un acto o norma por sí misma, sin necesidad de acudir a otro derecho afectado ${ }^{73}$. Siguiendo el artículo 19 No 2 de la Constitución, una diferencia de trato será inconstitucional cuando resulte arbitraria, esto es, caprichosa, irracional o no suficientemente justificada ${ }^{74}$. No es necesario, por tanto, que de esa diferencia arbitraria emane, adicionalmente, daño para otro derecho fundamental.

Ello es relevante en el tema que abordamos, pues, en materia de igualdad ante las cargas públicas, las limitaciones impuestas a las mismas en virtud de los derechos fundamentales, emanan tradicionalmente de la propiedad. Así, se considera que la igualdad ante las cargas protege a individuos cuando los efectos de aquélla sobre su propiedad, son excesivos o desproporcionados. Se omite así un análisis complementario: que la igualdad ante las cargas supone una exigencia mínima de igualdad de trato, independientemente de sus efectos. Por tanto, la imposición de cargas queda también sujeta a la observancia de exigencias propias de la igualdad constitucional, independientemente de su lesión adicional a la propiedad. En síntesis: una carga pública vulnerará la igualdad si establece una diferencia arbitraria.

El patrón de razonabilidad utilizado para evaluar una diferencia arbitraria presenta varias formulaciones, unas más estrictas que otras. En Chile, destaca la desarrollada por el TC desde Gratuidad Universitaria ${ }^{75}$, que identifica tres elementos: la diferencia de trato específica, su finalidad y el factor o criterio de distinción. Estos factores deben tener una relación sustancial y directa para excluir la arbitrariedad. Supongamos que una ley impone, a los dueños de terrenos aledaños a los cerros fiscales, la carga de permitir el libre acceso del público. La diferencia de trato sería dar libre acceso a la propiedad cuando otros propietarios no lo hacen. La finalidad sería permitir el uso público de ciertos bienes fiscales (cerros). El factor de diferencia sería la contigüidad de la propiedad a tales cerros. La relación entre los tres criterios es directa y sustancial, por lo que no habría una diferencia arbitraria. Ello no impide que surjan problemas de constitucionalidad desde la perspectiva de la propiedad.

A la inversa, supongamos que la ley impone a los Testigos de Jehová la carga de dejar un $0,001 \%$ de su propiedad, con un tope de 1 metro cuadrado fuera de los cercos de sus

\footnotetext{
71 McCrudden y Prechal (2009).

72 Aristóteles (2009) p. 684.

73 McCrudden y Prechal (2009) p. 11.

${ }^{74} \mathrm{La}$ afirmación no es exclusiva del derecho nacional. Por ejemplo, el TC alemán desde sus inicios uso la arbitrariedad para decidir si había infracción a la igualdad. MCCRUdden y Prechal (2009) p. 15.

75 Requerimiento de inconstitucionalidad, Ley de Presupuesto del Sector Público, Rol 2935-15 (2015) c. 36 y ss.
} 
inmuebles, con el fin de mejorar el espacio público. Desde la perspectiva de la propiedad, la carga es insignificante, pero no lo es desde la igualdad: la diferencia de trato no guarda una relación evidente con la finalidad, y peor aún, el criterio de diferenciación (religión), no evidencia conexión alguna con los otros factores. La carga sería inconstitucional, aunque su impacto en la propiedad fuese ínfima.

El estándar de racionalidad posee múltiples formulaciones en el Derecho comparado, pero un patrón admitido es la exigencia de conexión racional entre medios y fines. En cuanto a la intensidad del control, mientras más importante sea el derecho o bien en juego, más estricto habrá de ser el examen jurisdiccional sobre los motivos esgrimidos por la autoridad $^{76}$. Un caso ilustrativo es Nollan (1987). La Comisión de Costa de California exigió a los dueños de un sitio costero la cesión gratuita de una porción del terreno para establecer una servidumbre que favoreciera proteger la vista a la playa y permitir el libre paso del público hacia ella. La cesión gratuita era la exigencia que les permitiría erigir su vivienda en el terreno. El fallo sostuvo que la carga -ceder parte del terreno para servidumbre de pasocomo condición para levantar la prohibición de construir, simplemente no contribuía a mitigar el bloqueo de la vista, por lo cual la condición impuesta no guardaba conexión causal con fin perseguido por la norma. Como dice la sentencia:

"Es del todo imposible comprender de qué modo permitirle a la gente que se encuentra en la playa cruzar la propiedad de los Nollan sirve para reducir los obstáculos a la vista causados por la construcción de la nueva casa. Asimismo, es imposible comprender cómo ello debilita la 'barrera sicológica' para acceder a las playas públicas, o cómo ello ayuda a reducir la congestión que adicionalmente les causaría la construcción de la casa de los Nollan"77. El fallo dice que la construcción de la casa de los Nollan no era la causa que generaba el problema de acceso y vista del público a la playa, por lo que imponer la servidumbre a su propiedad mal podía servir como medio y condición para lograr el fin esgrimido que justificaría la prohibición ${ }^{78}$.

El estándar de conexión causal entre los fines y los medios adoptados parece exigir tres requisitos: (1) la concurrencia de un fin o interés estatal legítimo; (2) la conexión entre este interés y la restricción de uso de suelo adoptada para alcanzarlo; y (3) una mínima conexión entre el impacto de la construcción de la casa y la restricción al uso de suelo ${ }^{79}$. En efecto, el fallo rechaza la condición impuesta (cesión de parte del terreno) en gran medida porque tal limitación no reduce "los obstáculos a la vista causados por la nueva construcción de los Nollan" ${ }^{\circ}$. A falta de dicha exigencia de racionalidad, "la exacción adoptada por la autoridad administrativa "no podía considerarse como un ejercicio legítimo del poder de

\footnotetext{
76 McCrudden y Prechal (2009) pp. 49-50.

77 Nollan v. California CoAstal Commission (1987).

78 Nollan v. CALIFORNia COASTAL COMmission (1987) c. 837: "la propiedad protegida desaparece, con todo, si la condición [ceder parte del sitio] que sustituyó a la prohibición [de construir] fracasa notoriamente en lograr el fin promovido como justificación de la prohibición".

79 Nollan v. CaLifornia CoAstal Commission (1987).

80 Nollan v. California Coastal Commission (1987).
} 
policía" ${ }^{11}$. En fin, un límite relevante a la igualdad antes las cargas es la prohibición de las diferencias arbitrarias ${ }^{82}$, protegidas por el derecho a la igualdad, autónomamente considerado, sin perjuicio del impacto de tales diferencias sobre la propiedad.

\subsection{IGUALDAD DE DERECHOS}

La igualdad de derechos constitucionales se enfoca en la titularidad y goce de éstos ${ }^{83}$. No tiene carácter autónomo, pues su objeto no es proteger la igualdad en sí misma, sino la igualdad en función de otro derecho, el cual concentra la atención.

Nos parece que esta es la noción de igualdad tradicionalmente aplicada en materia de igualdad de cargas públicas. Como se ha ilustrado abundantemente, lo relevante en estos casos no ha sido la igualdad en sí, sino que la igualdad en el ejercicio y disfrute de la propiedad. En la medida que ese disfrute se entorpecía en forma excesiva, desproporcionada, etc., se estaría vulnerando la igualdad en el ejercicio del derecho.

No obstante, creemos que esta noción de igualdad ofrece aún nuevas posibilidades para limitar la imposición de cargas públicas. Primero, permite considerar otros derechos. Como decíamos, hasta ahora el foco ha estado centrado en la propiedad. Con todo, la igualdad de derechos puede extenderse a otros. Así, una carga pública podría vulnerar la igualdad de derechos por limitar excesivamente, por ejemplo, la libre iniciativa económica, la inviolabilidad del hogar, etc. Así, es posible un escrutinio más holístico de la carga y de su impacto sobre el conjunto de derechos.

En segundo lugar, la igualdad de derechos podría dar mayor flexibilidad argumentativa. Si bien esta igualdad se centra en el derecho afectado, siempre hay espacio para plantear problemas de igualdad, cuestión que puede convenir por razones estratégicas o de prueba. La experiencia de nuestro Tribunal Constitucional ilustra que, en ocasiones, el problema "accesorio" de igualdad sí puede ser suficientemente relevante para centrar la atención del juez, o para decidir casos difíciles. Más aún, el Tribunal Constitucional ha declarado con insistencia que las limitaciones a los derechos fundamentales deben someterse, entre otros requisitos, precisamente a la igualdad ${ }^{84}$.

Tercero, la igualdad de derechos permite gradualizar el control de las diferencias: desde la racionalidad a la proporcionalidad. Cuando algunos jueces lidian con derechos, suelen acudir a la proporcionalidad, no a la racionalidad. Así, mientras la igualdad nos lle-

\footnotetext{
81 Nollan v. California CoAstal Commission (1987) c. 837: “a menos que la condición impuesta por la autoridad sirva el mismo fin estatal al que sirve la prohibición de desarrollo inmobiliario, la restricción de construcción no es una regulación válida para el uso de suelo".

82 SAX (1964) p. 64. Quienes cuestionan la incidencia que podría tener la igualdad ante a las cargas en materia de regulaciones a la propiedad, lo hacen en gran medida porque admiten que el control judicial de la igualdad en la distribución de las cargas y beneficios públicos conduce inexorablemente a examinar la racionalidad de las distinciones y criterios adoptados por el legislador. DAVIDSON (2008) p. 5.

83 McCrudden y Prechal (2009) pp. 17 y ss.

84 REQUERIMIENTO DE INAPLICABILIDAD, LEY 19.970, ROL 1365-09 (2010), REQUERIMIENTO DE INAPLICABILIDAD, DeCRETo con Fuerza de LEY 164, Rol 541-05 (2006), ReQuerimiento de Diputados, Proyecto de Ley sobre Libertad de EXPREsión, Información y EJercicio del Periodismo, Rol 226-95 (1995), Requerimiento de SENADORES, LEY 18.695, ROL 228-95 (1995).
} 
va a aplicar un estándar habitualmente menos exigente, el involucramiento de un derecho "principal” permitiría elevar ese estándar de control.

\section{CRITERIOS DE IGUALDAD IDENTIFICADOS PARA EVALUAR LA CONSTITUCIONALIDAD DE LIMITACIONES AL DERECHO DE PROPIEDAD}

\subsection{INSUFICIENCIA DE LA GENERALIDAD ABSTRACTA DE LA NORMA LEGAL COMO CRITERIO DE IGUALDAD EN LA DISTRIBUCIÓN DE LAS CARGAS PÚBLICAS \\ Como toda norma legal, las regulaciones que limitan la propiedad, están concebidas} para regir sobre un número indeterminado de destinatarios, por lo que no solo genera sus efectos en el reclamante. Esta generalidad suele entenderse como una "presunción" de su igualdad: como se aplica a todos, no podría contener un trato o intención discriminatoria.

Con todo, estimamos que en esta materia, la generalidad tiende a perder densidad. No es que la carga se aplique a toda la población por igual, sino a sectores de ella que caen dentro de las hipótesis fácticas previstas en la norma (e.g., los propietarios de terrenos que deslindan con el mar). Por tanto, la "presunción" de igualdad de la generalidad, se atenúa en estas situaciones. Adicionalmente, la generalidad de las normas no parece un criterio suficiente que asegure el cumplimiento de la igualdad constitucional. A este respecto debe rescatarse la segunda parte de la fórmula aristotélica: los desiguales requieren un trato desigual, por lo que entregarles el mismo trato que al resto puede vulnerar la igualdad.

Así, hay ocasiones en que ciertos efectos derivados de aplicar una norma dan cuenta de la necesidad -desde la igualdad- de incorporar ciertas distinciones relevantes no previstas en la ley general y abstracta. Cesión de ejemplares (1981) es claro ejemplo. Allí, la categoría relevante para la ley, in abstracto, eran todos los editores, en el entendido que la carga era ínfima y el fin era razonable para la gran mayoría de los destinatarios de la norma. Sin embargo, no considerar la aplicación de la norma a la situación concreta de un grupo de editores -categoría no prevista en la ley- les habría significado soportar un sacrificio excesivo al pretender afectar con una carga semejante a un grupo de editores que no se encuentran en una situación similar a la de la generalidad de ellos. En fin, identificar la categoría efectivamente relevante de destinatarios de la norma es clave.

Ahora bien, esta reflexión tiene un correlato interesante en materia de igualdad constitucional, vinculada a la igualdad material, que exige considerar la realidad fáctica de los afectados por la norma.

Sin embargo, la igualdad material puede ser problemática, pues exige otorgar un tratamiento diferente, escapando así a la regla general en materia de igualdad constitucional. En otras palabras, lo normal es el trato igualitario, y por tanto, el trato desigual es lo excepcional y requiere justificación adecuada. En nuestro país, el desafío es mayor, ya que la Constitución no hace una mención expresa a la igualdad material. Más aún, el Tribunal Constitucional ha sido renuente a imponer al legislador la necesidad de establecer diferencias de trato para los diferentes ${ }^{85}$.

85 Díaz de Valdés (2019) pp. 118-123. 


\subsection{LA CATEGORÍA RELEVANTE IN ABSTRACTO NO CONTRIBUYE A DISCERNIR QUIENES ESTÁN EN UNA SITUACIÓN DE DESIGUALDAD EN CONCRETO}

Vimos que identificar la categoría relevante de destinatarios de una norma es clave para evaluar si la afectación que padece el propietario es comparable a la situación de los dueños que se encuentran en una situación similar. Esto se observa en Lucas (1992). El dueño de un lote frente al mar, reclama de una ley que, aprobada después de adquirir su terreno, le impide construir. Aunque el holding del fallo que declaró inconstitucional la norma se centró en la pérdida total del valor del bien, la perspectiva de igualdad fue relevante, tanto para la mayoría como para la disidencia.

El disidente dijo que la ley no "tenía como destinatarios a ningún propietario en particular, sino que regulaba el uso de las playas de todo el Estado" ${ }^{\prime 6}$. Como estaba destinada a todos los dueños que tuvieran terrenos en la zona de playa, se entendía que la carga era similar, pues la prohibición de construir regía indistintamente sobre los dueños de sitios construidos como de los terrenos no construidos ${ }^{87}$ : mientras a los primeros se les impedía agrandar la edificación, a los segundos se les impedía levantar una nueva construcción. La prohibición in abstracto era la misma para todos los destinatarios de la norma legal.

Para la mayoría, en cambio, la categoría relevante eran los propietarios efectivamente afectados a posteriori por la prohibición legal, sin importar cuán amplia o reducida fuese la categoría de dueños de sitios en zonas costeras en cuanto destinatarios generales de la ley. En el hecho, al propietario-reclamante le estaba impedido hacer (construir) aquello que todos los vecinos habían podido hacer, en circunstancias que la prohibición era posterior a la adquisición del terreno.

Lo relevante para la igualdad ante las cargas públicas no es que el afectado no pudo hacer lo que todos sus vecinos habían podido, sino que estaba prohibido hacer aquello que todos quienes se encontraban en una situación similar habían hecho. Para la mayoría, determinar la categoría relevante de destinatarios de la ley dependía de la situación fáctica de su aplicación: se encontraban en igualdad los propietarios que habían adquirido el bien raíz mientras no estaba afecto a la prohibición de construir. Esta decisión es consistente con un criterio jurisprudencial bastante extendido: que las regulaciones a la propiedad, aunque intensas, son constitucionales si la carga era inherente o estaba contenida en el título de adquisición del bien ${ }^{88}$.

Haber afrontado el caso en la perspectiva de igualdad abstracta habría significado equiparar al reclamante con aquellos que habían adquirido o adquirirían la propiedad con posterioridad a la vigencia de la norma, esto es, a sabiendas de la prohibición que les afectaba. La mayoría dijo que una ley "que prive a un terreno de todo uso económicamente beneficioso, puede no ser expropiatoria únicamente si los antecedentes muestran que la prohibición de uso de suelo existía al momento de adquirir el título" ${ }^{\text {9 }}$. Esto muestra que identificar la categoría relevante a partir de los destinatarios abstractos de la ley debilita el

\footnotetext{
86 Lucas v. South Carolina Coastal Council (1992) c. 1074.

87 Lucas v. South Carolina Coastal Council (1992) c. 1074-1075.

88 LuCas v. South Carolina Coastal Council (1992) c. 1029.

89 Lucas v. South Carolina Coastal Council (1992) c. 1027.
} 
discernimiento del juicio de igualdad -la igualdad entre iguales- atendido los efectos que su aplicación produce en concreto.

En fin, una carga legítimamente concebida in abstracto no está exenta de constituir en concreto una carga excesiva si las diferencias generadas por la ley dejan de considerar las distinciones relevantes que eviten que la carga dispar sea al mismo tiempo desigual, como ocurrió en Cesión de ejemplares $(1981)^{90}$. Al editor de libros de lujo, la ley hizo inviable su actividad económica y al dueño del sitio costero le impidió obtener provecho alguno. Al no estar en similar posición de soportar la carga, difícilmente ambos eran "iguales" al resto de los destinatarios genéricos de las respectivas normas legales.

\subsection{LA RECIPROCIDAD ENTRE VENTAJAS Y PÉRDIDAS SUPONE UN EQUILIBRIO ENTRE CARGAS Y BENEFICIOS}

Suele discutirse si la carga impuesta por una ley al propietario puede verse compensada por el beneficio que la norma le irroga. En el marco conceptual que utilizamos, esto puede vincularse a la igualdad de derechos. Como dijimos, esta igualdad pone el foco en el impacto del acto en cuestión sobre el derecho "adicional" a la igualdad. Una metodología para apreciar jurídicamente tal impacto podría considerar tanto los daños como los beneficios irrogados por la norma, sobre el dominio del afectado. Los casos de Monumentos históricos son ilustrativos.

Una ley que busca conservar y proteger el patrimonio histórico o arquitectónico no necesariamente infringe la igualdad al imponer al dueño del inmueble una carga considerablemente mayor que la de sus vecinos. A menos que el peso de la carga sea tanto como para impedirle seguir gozando de las ventajas que la propiedad le reporta en la dimensión que no sufre la limitación, una norma así parecería cumplir con el equilibrio ínsito de la reciprocidad: que la norma que establece la carga, junto con dejar subsistente las restantes facultades dominicales del afectado, le irroga, aunque indirectamente, el beneficio representado por el aspecto del bien común consistente en conservar el patrimonio cultural.

Para no generar problemas con la igualdad ante las cargas, la reciprocidad entre ventajas y cargas de una norma no puede perder de vista el equilibrio que ha de mantenerse entre la pérdida directa y el beneficio o ventaja indirecta. Siguiendo el mismo ejemplo, si mi propiedad es declarada Monumento, mi vecino como yo nos veríamos semejantemente beneficiados por una ley que busca conservar el patrimonio arquitectónico de ciertos edificios. Aunque la carga sería significativamente dispar en mi caso, el sacrificio que debo soportar parece justificarse en aras de un bien común que se alcanza permitiéndome seguir aprovechando las prerrogativas de la propiedad.

$\mathrm{Al}$ advertirse que parte del derecho de propiedad es, asimismo, parte de la contribución del bien público a alcanzar, difícilmente puede decirse que el propietario ha padecido una privación total o que ha sido tratado desigualmente. Esto, siempre que el sacrificio

\footnotetext{
90 Cesión de Ejemplares (1981) BVerfGE 58, 137, en BrÖHMER y otros (2012) p. 694: "igualdad ante la ley exige [...] que los elementos de la regulación [...] estén ordenados de modo que las diferencias generadas en la carga impuesta a los dueños y que las diferencias en el peso de sus intereses en comparación con los intereses del público, sean consideradas con las necesarias distinciones, evitando una carga desigual”.
} 
exigido para contribuir al bien común no le irrogue una carga excesiva, como sería el caso que el establecimiento de la carga le impidiera aprovechar las ventajas que le reporta el uso y goce del derecho. No habría beneficio directo como contrapartida de su sacrificio.

En la determinación de tales exigencias está el equilibrio que supone la función social de la propiedad. Si se le impone al dueño una carga significativa que no le permite aprovechar las ventajas que la propiedad le provee, se produce una situación como la de Monumentos Nacionales (1999), en que "el deber legal de conservar la propiedad, el derecho se transforma en una carga que el dueño tendrá que soportar con fundamento en el interés general, sin poder gozar de las ventajas del uso privado.”. Así, la carga de sobrellevar la conservación de la propiedad se torna excesiva al no brindar como contraparte la posibilidad de "gozar de las ventajas de un uso privado"91.

La reciprocidad entre ventajas y pérdidas parece no cumplirse si la carga que el dueño soporta en pos del bien común es de tal entidad que hace ilusorio el beneficio que, como contrapartida, le correspondería en aquella porción restante del derecho. Se infringe así la exigencia constitucional de que "los intereses del dueño afectado se encuentren equitativamente equilibrados con aquellos del público en general"92, que implica que "las limitaciones suponen el establecimiento de determinadas cargas al ejercicio de un derecho, dejándolo subsistente en sus facultades esenciales". Así, como dice el TC chileno, "la función social es un límite intrínseco de la propiedad"93.

Sin la exigencia de equilibrio, el criterio de reciprocidad, aplicado bajo la modalidad implícita de una ponderación entre costo-beneficio, corre el riesgo de transformarse en un estándar que pueda validar cualquier legislación de política pública por el hecho de conferir un beneficio público a gran escala ${ }^{94}$. En fin, si la carga impuesta por la norma es menor, esta podría verse compensada por el beneficio que la misma irroga a la sociedad y, por tanto, al mismo afectado. La cuestión se complejiza cuando el fin que busca la norma conlleva una carga o pérdida de tal magnitud o intensidad que altera el equilibrio que debe existir entre las ventas y cargas que se establecen. Algún grado de pérdida debe admitirse, pero una de gran magnitud impediría que se alcance la justa distribución entre ventajas y cargas, lo que podría constituir una infracción no solo a la igualdad ante las cargas, sino también al equilibrio que supone la función social de la propiedad.

\subsection{LA SEVERIDAD VERTICAL DE LA CARGA PÚBLICA COMO CRITERIO DE IGUALDAD}

Hasta aquí hemos evaluado cuando la carga pública es distribuida entre propietarios que se encuentran en una situación semejante ${ }^{95}$. Sin embargo, hay ocasiones en que

\footnotetext{
91 Monumentos Nacionales (1999) Sentencia BVerfGE 100, 226, en Schwabe (2009) p. 435.

92 Cesión de Ejemplares (1981) BVerfGE 58, 137, en BRÖHMER y otros (2012) pp. 693-694.

93 Requerimiento de Diputados y Senadores, Decreto Supremo No 1 de 1996 del Ministerio de Bienes Nacionales, Rol 245-96 (1996) y Requerimiento de Diputados y Senadores, DeCreto Supremo No 1 DE 1996 DEL Minsterio de BIENES NACIONALES, ROL 246-96 (1996) c. $22^{\circ}$ y $25^{\circ}$; REQUERIMIENTO DE INAPLICABILIDAD, DECRETO CON FUERZA DE LEY 850, ROL 1991-11 (2012) c. 42; REQUERIMIENTO DE INAPLICABILIDAD, DECRETO CON FUERZA DE LEY 850, ROL 1993-11 (2012) c. $42^{\circ}$ y REQUERIMIENTO DE INAPLICABILIDAD, LEY 17.288, ROL 2299-12 (2014) c. $7^{\circ}$.

94 Oswald (1997) p. 1522.

95 Ball y Reynolds (2006) p. 1533.
} 
el carácter desigual de la carga emana de la severidad del impacto concreto que la norma produce en uno de sus destinatarios. El impacto de una ley puede ser muy significativa para el afectado, aunque el sacrificio sea marginal en términos comparativos. A la inversa, una reducción comparativamente considerable que padezca el afectado, puede no ser excesiva para él, aisladamente considerado.

Así, una reducción salarial porcentualmente leve y aplicada proporcionalmente a todo el sector público, podría ser más o menos significativa para la mayoría, pero devastador para los funcionarios de rentas más bajas. A esto se ha referido el TEDH en casos de reducción o suspensión de remuneraciones o beneficios sociales del sector público, cuando se ha pronunciado exigiendo que las señaladas políticas públicas deben mantener los medios suficientes de subsistencia de los afectados.

Vimos que para el TEDH no se cumple el justo equilibrio entre el individuo y la sociedad cuando los reclamantes soportan "una carga individual y excesiva" ${ }^{16}$. El factor crucial para evaluar una regulación al derecho de propiedad es que como "carga individual" no sea excesiva. La determinación de la desproporción depende de considerar los efectos de la carga en el afectado, individualmente considerado.

Durante la crisis económica europea, y con el fin de equilibrar los déficits presupuestarios, algunos países adoptaron medidas de reducción y/o suspensión de salarios y pensiones que tenían como destinatarios a los funcionarios públicos. Las normas significaron recortes de beneficios ya existentes, especificados indubitadamente como propiedad ${ }^{97}$ según el TEDH. Focalizado el control jurídico en el impacto concreto de la norma respecto del reclamante, no de su situación comparativa, lo relevante no fue evaluar cuán representativa era la disminución dentro del total del beneficio o de la remuneración, sino que su situación concreta no fuese inferior a cierto estándar, aunque el recorte o pérdida haya sido ínfimo.

Tanto en los casos en que se declaró inadmisible la acción como en los que ésta prosperó, el exceso se determinó en base a si la medida dejaba al reclamante con suficientes medios de subsistencia ${ }^{98}$. Así, en Koufakis y ADEDY vs. Grecia (2013) la acción es desestimada tras observarse que el recorte no puso a los reclamantes en una situación de carecer de medios suficientes para vivir ${ }^{99}$ y en Da Silva Carvalho Rico v. Portugal (2015), se estimó que el reclamante no había padecido una merma sustancial en sus ingresos por lo que no se verifica la desproporción ${ }^{100}$. Por su parte, en Da Conceição Mateus vs. Portugal (2013) considera que la medida no altera la tasa de pensión básica de los afectados, que sigue per-

\footnotetext{
96 William LithGOW et AL. VS. ReINo UNIDO (1986) párr. 120.

97 El TEDH ha dado al término "posesiones", del art. $1^{\circ}$ del Protocolo un alcance amplio, que no solo protege la cosa, sino también los intangibles. STEC Y OTROS VS. REINO UNIDO (2006) párr. 49-56: en la Convención, el término "posesión" debía ser interpretado según el concepto de derechos pecuniarios del artículo 6 de la Convención. Koua PoIrRez vs. FranCIA (2003) párr. 33 y 42, dijo que es propiedad un beneficio para discapacitados.

98 Palmstorfer (2014) p. 130.

99 KOUfakis y ADEDY VS. GRECIA (2013) párr. 46.

100 Da Silva Carvalho Rico vs. Portugal (2015) párr. 45.
} 
cibiéndose por 12 meses, suspendiéndose por dos años las cuotas 13 y $14^{101}$. Por último, en Savickas y otros vs. Lituania (2013) también fue decisivo que el acto fuera transitorio y, lo relevante, que no supusiera una amenaza para los medios de vida de los afectados ${ }^{102}$.

Siguiendo la misma tónica, N.K.M. vs. Hungría (2013) y R.S.Z. vs. Hungría (2013) fueron acogidos, al estimarse que se trataba de una reducción visiblemente significativa de ingresos de los reclamantes. Aplicada en un momento de particular dificultad como es el desempleo, los expuso, "de forma probable", a dificultades personales sustanciales ${ }^{103}$. En ambos casos, se añadió, como un factor adicional de la infracción, el trato diferente recibido por el reclamante en comparación a la mayoría de la población, que "no fue obligada a contribuir, en una medida comparable, a la carga pública" 104 .

Desde la teoría de la igualdad, podemos apelar a la noción de igualdad material o fáctica, la cual apunta a lograr la equiparación de las condiciones de facto de las personas, más allá de la formalidad del Derecho ${ }^{105}$. Para ello, introduce tratamientos desiguales que intentan forzar una mayor igualdad en la realidad concreta. Esta noción de igualdad es excepcional, y debe ser exhaustiva y convincentemente justificada.

En fin, en su aplicación a las cargas públicas, podemos señalar que, si aquellas se presentan como un avance hacia la mayor igualdad fáctica, entonces requieren una cuidada justificación capaz de sostener su excepcionalidad. Por otra parte, cargas públicas que, en su aplicación a la realidad fáctica, causen un impacto sustantivamente desigual -en su intensidad- entre sus destinatarios, incluso privándolos de condiciones mínimas para el ejercicio efectivo de sus derechos (como en algunos de los casos descritos más arriba), serían incompatibles con esta visión de igualdad. Así, la igualdad material o fáctica se convertiría en un límite adicional a las cargas públicas. Destacamos, en todo caso, que la naturaleza excepcional de esta igualdad en el ámbito constitucional, dificulta recurrir a ella como límite efectivo a la labor del legislador.

\section{CONCLUSIONES}

1. La garantía de la igualdad ante las cargas públicas exige la formulación de límites a los gravámenes o restricciones que se imponen a la propiedad en nombre de su función social.

2. Si bien la invocación a la función social implica suponer que las cargas que se imponen en su nombre benefician también al afectado, ya que persiguen el provecho de la Sociedad en su conjunto, aquellas no pueden redundar en un desequilibrio excesivo en el

\footnotetext{
101 Da Conçeicão Mateus y Santos Januario vs. Portugal (2013) párr. 27-28. Aquí, el trato "especialmente ventajoso" para un grupo de personas en comparación al resto fue digno de una mención secundaria en la sentencia, como se observa en párr. 24.

102 SAVICKAS Y OTROS VS. LITUANIA (2013) párr. 94.

103 N.K.M. vS. HuNGRÍ (2013) párr. 70; R.S.Z. vs. HuNGRÍ (2013) párr. 59.

104 Palmstorfer (2014) p. 128. En ambos casos, el TEDH desecha pronunciarse separadamente respecto del art. 14 del CEDH (Prohibición de discriminación), pues dice que se hará cargo de la desigualdad al evaluar la aplicación del acto reclamado y así reforzar su juicio de desproporcionalidad del mismo (N.K.M. VS. HUNGRIA (2013) párr. 84 y R.S.Z. VS. HUNGRÍA (2013) párr. 70)

105 McCrudden y Preschal (2009), Fredman (2001b).
} 
tratamiento de los intereses del afectado y del resto de la Sociedad, quién recibe los beneficios - pero no los costos- de la carga pública.

3. Abundan ejemplos, tanto en la jurisprudencia nacional como comparada, acerca de cómo la función social de la propiedad supone equilibrar los intereses del dueño afectado con los de la Sociedad. El análisis será siempre contextual al caso concreto.

4. Este equilibrio exige que la imposición de cargas públicas quede sujeta a diversos límites constitucionales. Si bien lo tradicional ha sido desprender aquellos del respeto al derecho de propiedad, la igualdad constitucional -en sus diversas especies- provee límites adicionales a la imposición de cargas públicas. Así, lo ilustran diversos casos de derecho comparado, tanto alemán como norteamericano.

5. Desde una perspectiva de igualdad constitucional tradicional, no basta que la carga pública no afecte severamente la propiedad, sino que además no debe constituir, en sí misma, una diferencia arbitraria. Ello es independiente de la magnitud de sus efectos sobre la propiedad. En cuanto al examen de racionalidad para excluir la arbitrariedad, la experiencia comparada demuestra que, si bien varía en componentes e intensidad, exige siempre una sólida conexión entre principios y medios legítimos.

6. Desde una perspectiva de igualdad constitucional como igualdad de derechos, sería posible someter a las cargas públicas a examen respecto de la infracción de otros derechos diversos a la propiedad. Adicionalmente, permitiría elevar el estándar de control, desde la racionalidad -propia de la igualdad-, al exceso que suele aplicarse en la protección de otros derechos fundamentales.

7. Desde la perspectiva de la igualdad material, excepcional en nuestro sistema, podría ser inconstitucional imponer una carga pública que, en los hechos, afecte desproporcionadamente -en su intensidad- a personas o grupos desaventajados. A la inversa, la igualdad material, exigentemente justificada, podría dar pie para imponer cargas públicas que produzcan, en la realidad, una mayor igualdad en la población.

8. Por último, que legislador y juez pueden colaborar en la determinación de los límites a las cargas públicas. El primero, brindando criterios generales que orienten al segundo. La judicatura, por su parte, no sólo será siempre insustituible en la apreciación y resolución del caso concreto, sino que también está llamada a desarrollar criterios y estándares uniformes que provean mayor certeza en esta incierta área del derecho.

\section{BIBLIOGRAFÍA CITADA}

Aldunate Lizama, Eduardo (2006): "Limitación y expropiación: Scilla y Caribdis de la dogmática constitucional de la propiedad”, Revista Chilena de Derecho, vol. 33, No 2: pp. 202-215.

Aldunate Lizama, Eduardo (2000): "Consecuencias constitucionales de la Doctrina sobre la responsabilidad objetiva del Estado”, Revista de Derecho, vol. 1, No 2: pp. 1-8.

AleXAnder, Gregory (2006): The Global debate over Constitutional Property: Lessons from American Takings Jurisprudence (Chicago, Chicago University Press).

Allen, Tom (2005): Property and the Human Rights Act 1998 (Oxford, Hart Publishing). 
Arai-Takahashi, Yutaka (2002): The Margin of Appreciation Doctrine and the Principle of Proportionality in the Jurisprudence of the ECHR (Antwerp, Intersentia).

Aristóteles (Siglo IV a.c): La Politica (trad. Pedro Simón, Madrid, Ediciones Nuestra Raza). Aristóteles (2009): Ética a Nicómaco (4a ed. Madrid, Tecnos).

Ball, Carlos. \& Reynolds, Laurie (2006): "Exactions and burden distribution in takings law", William \& Mary Law Review, vol. 47: pp. 1513-1585.

BaraK, Aharon (2015): Human Dignity (Cambridge, Cambridge University Press).

Barcelona Llop, Javier (2017): "El Tribunal Europeo de Derechos Humanos y la pobreza", Revista Interdisciplinar de Estudios Histórico-Jurídicos, No 20: pp. 323-370.

BröHmer Jürgen, Hill, Clauspeter y Spitzkatz, Marc (2012): 60 Years German Basic Law: The German Constitution and its Court Landmark Decisions of the Federal Constitutional Court of Germany in the Area of Fundamental Rights (Berlin, Konrad-Adenauer-Stiftung).

Bronfman, Alan, Martínez, José Ignacio y Nuñez, Manuel (2012): Constitución Política Comentada (Santiago, Abeledo Perrot).

Cea Egaña, José Luis (2012): Derecho Constitucional Chileno, Tomo II (Santiago, Ediciones UC, $2^{\text {a }}$ edición).

Cordero Quinzacara, Eduardo (2006): "La dogmática constitucional de la propiedad en el derecho chileno", Revista de Derecho Valdivia, vol. 19, No 1: pp. 125-148.

Covarrubias Cuevas, Ignacio (2014): “¿Puede la dignidad humana ser un principio comúnmente compartido en materia de adjudicación constitucional?”, Actualidad Jurídica, vol. 15, No 29: pp. 147-165.

Dana, David y Merrill, Thomas (2002): Property takings (Foundation Press; $1^{\text {st }}$ Edition).

DAvidson, Nestor M. (2008): "The problem of equality in takings", Fordham University School of Law, vol. 102, No 1: pp. 1-53.

De GraAf, Regien (2014): "Compensation for expropriation: how compensation reflects a vision on property”, European Property Law Journal, vol. 3: pp. 3-33.

Delaveau Swett, Rodrigo (2006): "La expropiación regulatoria en la experiencia norteamericana", Revista chilena de Derecho, vol. 33, No 3: pp. 411-438.

Díaz de Valdés Julia, José Manuel (2019): Igualdad Constitucional y No Discriminación (Valencia, Tirant Lo Blanch).

ECHEVERría, John (2006): "The triumph of Justice Stevens and the principle of generality", en BROOKs, Richard (edit.), The Supreme Court and taking: four essays (Vermont Law School) pp. 22-40.

FEe, John E. (2003): "The takings clause as a comparative right", Southern California Law Review, vol. 76, No 5: pp. 1003-1066.

Fermandois Vhöringer, Arturo (2006): Derecho Constitucional Económico, Garantías Económicas, Doctrina y Jurisprudencia, Tomo I (Santiago, Editorial Pontificia Universidad Católica de Chile, $2^{\text {a }}$ edición).

Gaba, Jeffrey M. (2007): "Taking justice and fairness seriously: distributive justice and the takings clause", Craigthon Law Review, vol. 40: pp. 569-594.

García Roca, Joaquín (2010): El margen de apreciación nacional en la interpretación del Convenio Europeo de Derechos Humanos: soberania e integración (Madrid, Civitas). 
Gómez Heredero, Ana (2007): La seguridad social como derecho humano: la protección ofrecida por el Convenio Europeo de Derechos Humanos (Estrasburgo, Consejo de Europa).

Guiloff Titiun, Matías (2018): "La privación de atributos y facultades esenciales del dominio como estándar de control sobre las intervenciones al derecho de propiedad privada", Estudios Constitucionales, vol. 16, № 2: pp. 271-306.

Hanoch, Dagan (1999): “Takings and distributive justice", Virginia Law Review, vol. 85, No 5: pp 741-804.

LegG, Andrew (2012): The Margin of Appreciation in International Human Rights Law: Deference and Proportionality (Oxford U.K., Oxford University Press).

López EsCARCENA, Sebastián (2014): Indirect expropriation in international law. Leuven global governance (Cheltenham UK, Northampton MA USA, Edward Elgar).

LuBENS, Rebeca (2007): "The social obligations of property: a comparison of German and U.S. Law", Arizona Journal of International \& Comparative Law, vol. 24, № 2: pp. 389-449.

Marmolejo GonzÁlez, Críspulo (2003): "El problema de las expropiaciones regulatorias y sus implicancias en el sistema de Inversión Extranjera”, Gaceta Jurídica, № 282: pp. 7-12.

Matute, Claudio (2014): Expropiaciones Regulatorias (Santiago, Thomson Reuters $1^{\text {a }}$ edición).

McCrudden, Christopher (2014): Understanding Human Dignity (Oxford, Oxford University Press).

McCrudden, Christopher y Prechal, Sacha (2009): The Concepts of Equality and NonDiscrimination in Europe: A practical approach (Brussels, European Commission).

Michelman, Frank (2012): "Constitutional protection for property rights and the reasons why: distrust revisited”, Brigham-Kanner Property Rights Journal, vol. 1: pp. 217-237.

Millán Puelles, Antonio (1982): Persona Humana y Justicia Social (Madrid, Rialp).

Mohor Abuauad, Salvador (1989): "Taxonomía a las limitaciones al dominio y derecho de indemnización”, Revista chilena de Derecho, vol. 16, No 2: pp. 283-308.

Montt Oyarzún, Santiago (2009): State liability in investment treaty arbitration: global constitutional and administrative law in the bit generation (Oxford, Hart Publishing).

Nogueira Alcalá, Humberto (2009): "Los derechos económicos, sociales y culturales como derechos fundamentales efectivos en el constitucionalismo democrático latinoamericano", Revista de Estudios Constitucionales, No 2: pp. 143-205.

OsWALD, Lynda (1997): "The role of the harm/benefit and average reciprocity of advantage rules in takings analysis", Vanderbilt Law Review, vol. 50: pp. 1450-1524.

Palmstorfer, Rainer (2014): "Austerity measures on trial: On the compatibility of austerity measures with the European Convention of Human Rights", Revista electrónica de Direito Público, vol. 1, No 3: pp. 122-134.

Peña Torres, Marisol (2016): "La jurisprudencia de valores del Tribunal Constitucional", en Fermandois Vöhringer, Arturo (edit.), Principios, Valores e Instituciones (Ediciones Universidad Católica de Chile) pp. 173-184.

Ponce de León, Viviana (2014): "La problemática invocación a la confianza legítima como límite a la potestad legislativa”, Revista de Estudios Constitucionales, vol. 12, No 1: pp. 429-471. 
Ponce de León, Viviana (2015): "La noción de carga pública y su función en la jurisprudencia del Tribunal Constitucional chileno", Revista Chilena de Derecho, vol. 42, No 3 : pp. 843-872.

Quezada Rodríguez, Flavio (2018): "Bases constitucionales de la expropiación”, en HenRíquez, Miriam y Rajevic, Enrique (Coord.), Derecho de Propiedad: Enfoques de Derecho Público (Santiago, DER-Universidad Alberto Hurtado) pp. 87-103.

Rajevic Mosler, Enrique Petar (2018): “¿Nulidad o responsabilidad?: El desfiladero de las limitaciones del derecho de propiedad”, en Henríquez, Miriam y Rajevic, Enrique (coord.) Derecho de Propiedad: Enfoques de Derecho Público (Santiago, DER-Universidad Alberto Hurtado) pp. 147-163.

Rose, Carol M. (1984): "Mahon reconstructed: why the takings issue is still a muddle", Southern California Law Review, vol. 57: pp. 561-599.

SAX, Joseph (1964): "Taking and the police power", Yale Law Journal, vol. 74: pp. 36-76.

SCHWABE, Jürgen (2009): Jurisprudencia del Tribunal Constitucional Federal Alemán (Berlín, Konrad Adenauer-Stiftung).

Singer, Joseph W. (2015): "Justifying Regulatory Takings", Ohio Northern University Law Review, vol. 41: pp. 601-670.

Sluysmans, Jacques, Bosma, Willem, Timmer, Matthijs y Van Triet, Nikky (2015): "The rule of law: Protection of property”, en Haentjens, Matthias y Wessels, Bob (edits.), Research handbook on Crisis Management in the Banking Sector (Edward Elgar Publishing) pp. 348-371.

Sluysmans, Jacques, Verbist, Stijn y De GraAf, Regien (2014): "Compensation for expropriation: how compensation reflects a vision on property", European Property Law Journal, vol. 3, No 1: pp. 3-33.

Zuñiga Urbina, Francisco (2013): "Comentario a la sentencia del Tribunal Constitucional sobre requerimiento de inaplicabilidad del inciso final del artículo 41 del DFL 850 de 1997 del Ministerio de Obras Públicas”, Anuario de Derecho Público, No 1: pp. 143-172.

\section{JURISPRUDENCIA CITADA}

JURISPRUDENCIA EUROPEA

SpORRONG Y LÖNNROTH Vs. SueCIA (1982). Corte Europea de DD.HH., No 7151/75, 23 de septiembre de 1982.

JAMES vs. REINO UNIDO (1986). Corte Europea de DD.HH., No 8793/79, 21 de febrero de 1986.

William Lithgow et al. vs. Reino Unido (1986). Corte Europea de DD.HH., No 9405/81, 8 de julio de 1986.

TRE TRakTÖReR AkTiebolag vs. SWEDEN (1989). Corte Europea de DD.HH., No 10873/84, 7 de julio de 1989.

Monasteries vs. GRECIA (1994). Corte Europea de DD.HH., No 13092/87, 9 de diciembre de 1994.

Chassagnou vs. Francia (1999). Corte Europea de DD.HH., № 25088/94, 29 de abril de 1999. 
Immobiliare Saffi vs. Italia (1999). Corte Europea de DD.HH., No 22774/93, 28 de julio de 1999.

Beyeler VS. Italy (2000). Corte Europea de DD.HH., No 33202/96, 5 de enero de 2000. Sentencia BverfG 1, BvR 558/91 del 26 de junio de 2002.

Koua Poirrez vs. Francia (2003). Corte Europea de DD.HH., No 40892/98, 30 de septiembre de 2003.

PRAVEDNaYA Vs. Rusia (2004). Corte Europea de DD.HH., No 69529/01, 18 de noviembre de 2004.

SolodyuK vs. Rusia (2005). Corte Europea de DD.HH., No 67099/01, 12 de julio de 2005.

Stec y otros vs. ReINo UNIDO (2006). Corte Europea de DD.HH., No 65731/01, 12 de abril de 2006.

Hutten-Czapsk vs. Polonia (2006). Corte Europea de DD.HH., No 35014/97, 19 de junio de 2006.

URBÁRSKA Obec Trenčlanske BiskUpice vs. Eslovaquia (2007). Corte Europea de DD.HH., No 74258/01, 27 de noviembre de 2007.

Turgut and others vs. Turquía (2008). Corte Europea de DD.HH., No 1411/03, 8 de julio de 2008.

Druzstevini Zalazna Pria and Others vs. República Checa (2008). Corte Europea de DD.HH., No 72034/01, 31 de julio de 2008.

Forminster ENTERPRises Limited vs. CZECH Republic (2008). Corte Europea de DD.HH., No 38238/04, 9 de octubre de 2008.

Perdigão vs. Portugal (2010). Corte Europea de DD.HH., No 24768/06, 16 de noviembre de 2010.

Seryavin y otros vs. Ukrania (2011). Corte Europea de DD.HH., No 4909/04, 11 De FeBRERO DE 2011.

SALIBA AND OTHERS vs. MALTA (2011). Corte Europea de DD.HH., No 20287/10, 22 de noviembre de 2011.

Althoff and others vs. Alemania (2011). Corte Europea de DD.HH., No 5631/05, 8 diciembre 2011.

LindHeim and others vs. Noruega (2012). Corte Europea de DD.HH., No 13221/08, 12 de junio de 2012.

KoufakIS y ADEDY vs. GRECIA (2013). Corte Europea de DD.HH., No 57665/12, 7 de mayo de 2013.

N.K.M. vs. Hungría (2013). Corte Europea de DD.HH., No 66529/11, 14 de mayo de 2013.

R.S.Z. vs. Hungría (2013). Corte Europea de DD.HH., No 41838/11, 2 de julio de 2013.

Da Conceição Mateus y Santos Januário vs. Portugal (2013). Corte Europea de DD.HH., No 62235/12, 8 de octubre de 2013.

Savickas y otros vs. Lituania (2013). Corte Europea de DD.HH., No 66365/09, 15 de octubre de 2013.

Da Silva Carvalho Rico vs. Portugal (2015). Corte Europea de DD.HH., No 13341/14, 1 de septiembre de 2015. 
JURISPRUdenCia NorTEAmERICANA

PenNsylvania CoAl Co. v. Mahon, 260 U.S. 393, 415 (1922).

Armstrong V. United States, 364 U.S. 40, 49 (1960).

Penn Central Transportation Co. v. New York City, 438 U.S 104, 133-134 (1978).

LoRETTO V. TELEPROMTER MANHATTAN CATV CORP., 458 U.S. 419 (1982)

Nollan v. CALIFORNIA COASTAL COMMisSion., 483 U.S. 825, 838-839 (1987).

Lucas v. South Carolina Coastal Council, 505 U.S. 1003, 1015-20 (1992).

LiNGLE V. CheVRon U.S.A. INC., 544 U.S. 528, 542 (2005).

\section{Jurisprudencia Chilena}

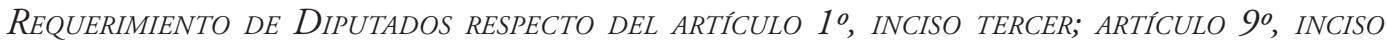
PRIMERO; ARTÍCULO 20, INCISO SEGUNDO, Y ARTÍCULO 43, INCISO SEGUNDO, DEL PROYECTO DE LEY SOBRE "LIBERTAD DE EXPRESIÓN, INFORMACIÓN Y EJERCICIO DEL PERIODISMO" (1995): Tribunal Constitucional Chileno, Rol No 226-95, 30 de octubre de 1995.

Requerimiento de Senadores respecto del artículo 1º, NoA 4 Y 8 del Proyecto de LeY que MODIFICA LA LEY No 18.695, ORGÁNICA CONSTITUCIONAL DE MUNICIPALIDADES, QUE CONTENIDO EN EL BOLETÍN No 1674-06, EN LO RELATIVO A LA GENERACIÓN DE AUTORIDADES (1995): Tribunal Constitucional Chileno, Rol No 228-95, 15 de diciembre de 1995.

Requerimiento de Diputados y Senadores respecto del Decreto Supremo No 1, de 10 de enero de 1996, del Ministerio de Bienes NaCionales, publicado en el Diario Oficial de 6 DE AGOSTO DEL MISMO AÑO (1996): Tribunal Constitucional Chileno, Rol No 245-96, 2 de diciembre de 1996.

Requerimiento de Diputados y Senadores respecto del Decreto Supremo No 1, de 10 de enero de 1996, del Ministerio de Bienes NaCionales, publicado en el Diario Oficial de 6 dE AGOSTO DEL MISMO AÑO (1996): Tribunal Constitucional Chileno, Rol No 246-96, 2 de diciembre de 1996.

ReQuerimiento de SENADORES RESPECTO DEL DECRETO SuPREMo No 171, DE FECHA 5 DE DICIEM-

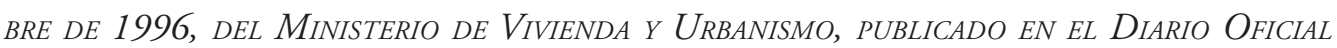
DE 17 DE ENERO DE 1997 (1997): Tribunal Constitucional Chileno, Rol No 253-97, 15 de abril de 1997.

Quintana Olivares, Elia y otros con Fisco (2000): Corte Apelaciones de Santiago, Rol 11144-2002.

REQUERIMIENTO DE INAPLICABILIDAD PRESENTADO POR LA CORTE DE APELACIÓN DE SANTIAGO RESPECTO DEL INCISO DEL ARTÍCULO 42 DEL DFL No 164, DE 1991 (LEY DE CONCESIONES), EN RELACión a LA CAUSA CARATULADA AUTOPISTA CENTRAL S.A. CON SERVICIO DE MECANICA MANTEN-

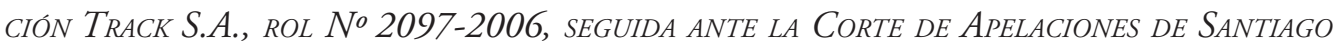
(2006): Tribunal Constitucional Chileno, Rol No 541-05, 26 de diciembre de 2006.

REQUERIMIENTO DE INAPLICABILIDAD PRESENTADO POR EMPRESA ELÉCTRICA PANGUIPULLI S.A. RESPECTO DEL ARTÍCULO $3^{\circ}$ TRANSITORIO dE LA LEY No 19.940, EN LA CAUSA CARATULADA "HQI Transelec S.A. con Empresa ElÉctrica Panguipulli S.A." QUe se sigue ante la Corte de 
Apelaciones de SANTiago (2007): Tribunal Constitucional Chileno, Rol No 505-06, 6 de marzo de 2007.

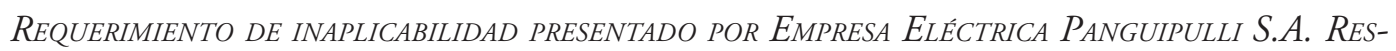

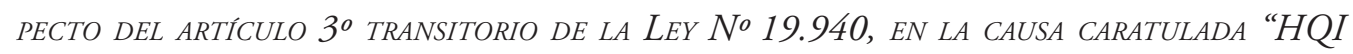
Transelec S.A. con EMpresa ElÉctrica PANGUipulli S.A." QUE SE sigue ante la Corte DE Apelaciones de SANTiago (2007): Tribunal Constitucional Chileno, Rol No 506-06, 6 de marzo de 2007.

REQUERIMIENTO DE INAPLICABILIDAD POR INCONSTITUCIONALIDAD PRESENTADO POR FERNANDO COLOMA REYES Y OTROS RESPECTO DEL ARTÍCULO $4^{\circ}$ DE LA LEY No 18.549 Y EL ARTÍCULO 29 DE LA LEY No 18.669 en la CAUSA CARATUlada LAGOS, Hipólito Y Otros CON INP, ROL No 18.828-06, SEGUIDA ANTE EL $7^{\circ}$ JUZGado CIVIL DE SANTIAGO (2007): Tribunal Constitucional Chileno, Rol No 790-07, 11 de diciembre de 2007.

REQUERIMIENTO DE INAPLICABILIDAD POR INCONSTITUCIONALIDAD DE AGRÍCOLA BAUZA S.A. RES-

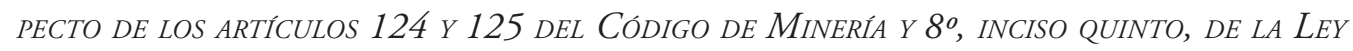
Orgánica Constotucional de Concesiones Mineras, No 18.097, en EL JUICIO ANTE EL Tecer Juzgado de Letras de OVAlle, Rol 85-2004, caratulado Domancic DragiceVic, Drago, CoN BAUZA ÁlVAREZ, LORENZO (2009): Tribunal Constitucional Chileno, Rol No 1284-08, 24 de septiembre de 2009.

REQUERIMIENTO DE INAPLICABILIDAD POR INCONSTITUCIONALIDAD DE GUSTAVO IVAN QUILAQUEO Bustos RESPECTO DE LOS ARTÍCULOS 5o, $6^{\circ}, 16^{\circ}, 17^{\circ}, 18^{\circ}$ Y $1^{\circ}$ TRANSITORIO, INCISO SEGUNDO,

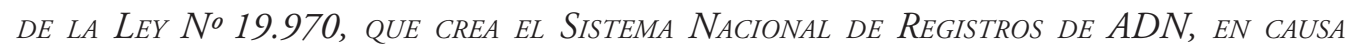
en actual conocimiento de la Corte Suprema bajo eL Rol de ingreso No 1.972-2009 (2009): Tribunal Constitucional Chileno, Rol No 1365-09, 8 de abril de 2010.

ReQUeRIMIENTO DE INAPLICABILIDAD POR INCONSTITUCIONALIDAD DE SilVIa QuiRoz Lozano, RESPECTO DEL ARTÍCULO 309 deL Código de AGUAS, en LA CAUSA ROL No 2373-04, seGUIDA ante el Segundo Juzgado de Letras en lo CiVIL de Curicó, aCtualmente ante la Corte SUPREMA EN RECURSOS DE CASACIÓN EN LA FORMA Y EL FONDO (2010): Tribunal Constitucional Chileno, Rol No 1309-09, 20 de abril de 2010.

REQUERIMIENTO DE INAPLICABILIDAD POR INCONSTITUCIONALIDAD PRESENTADO POR JORGE BEYTIA Moure EN REPRESENTACIÓN DE METROGRAS S.A., RESPECTO DEL INCISO FINAL DEL ARTÍCULO 41 DE DFL No 850 de 1997 del Ministerio de OBRAs Públicas, QUE FIJA TEXTO REFUNDIDO DE LS LEYES 19.474, 15.840, 19.020 Y LOS DFL No 206 DE 1960, No 870 DE 1975 Y 164 DE 1991, ACTUAL LEY ORGANICA DE DICHO MINISTERIO, EN LOS AUTOS ROL No 34.594-2009 sobre Juicio de haCienda, CARATUlados Fisco de Chile con Metrogas S.A., DEL QUE CONOCE EL $7^{\circ}$ JuZGado CIVIL DE SANTIAGO (2011): Tribunal Constitucional Chileno, Rol No 1991-11, 24 de julio de 2012.

REQUERIMIENTO DE INAPLICABILIDAD POR INCONSTITUCIONALIDAD PRESENTADO POR EMPRESA NACIONAL DE TELECOMUNICACIONES S.A. ENTEL, RESPECTO DEL INCISO FINAL DEL ARTICULO 41 DEL DECRETO CON FUERZA DE LEY No 850 de 1997, QUE FIJA TEXTO REFUNDIDO, COORDINADO Y SISTEMATIZADO DE LA LEY No 15.840, DE 1964, Y DEL DFL No 206 DE 1960, SOBRE CONSTRUCCIÓN Y CONSERVACIÓN DE CAMINOS, ACTUAL LEY ORGÁNICA DEL MiNSTERIO DE OBRAS PúbLICAS (EN ADELANTE LOMOP), EN LOS AUTOS ROL No 286-2011 SOBRE RECURSO DE CASACIÓN EN LA FORMA Y EN EL FONDO CARATULADOS FISCO CON EMPRESA NACIONAL DE TELECO- 
municACIONES S.A., DEL QUE CONOCE LA CORTE SUPREMA (2012): Tribunal Constitucional Chileno, Rol No 1993-11, 24 de julio de 2012.

REQUERIMIENTO DE INAPLICABILIDAD POR INCONSTITUCIONALIDAD PRESENTADO POR EMPRESA NACIONAL DE TELECOMUNICACIONES S.A. "ENTEL", RESPECTO DEL "INCISO FINAL DEL ARTÍCULO 41 DEL DECRETO CON FUERZA DE LEY No 850 DE 1997, QUE FIJA TEXTO REFUNDIDO, COORDINADO Y SISTEMATIZADO DE LA LEY No 15.840, DE 1964, y DEL DFL No 206 DE 1960, SOBRE CONSTRUCCIÓN Y CONSERVACIÓN DE CAMINOS, ACTUAL LEY ORGÁNICA DEL MiNSTERIO DE OBRAS Públicas (EN ADELANTE LOMOP)", EN LOS AUTOS ROL No 3819-2010 SOBRE RECURSO DE CASACIÓN EN LA FORMA Y APELACIÓN CARATULADOS "FISCO CON EMPRESA NACIONAL DE TELECOmunicaCiones S.A.", de QUE CONOCE LA CORTE DE APELACIONES DE SANTIAGo (2012): Tribunal Constitucional Chileno, Rol No 2043-11, 24 de julio de 2012.

REQUERIMIENTO DE INAPLICABILIDAD POR INCONSTITUCIONALIDAD PRESENTADO POR EMPRESA NACIONAL DE TELECOMUNICACIONES S.A. "ENTEL", RESPECTO DEL "INCISO FINAL DEL ARTÍCULO 41 DEL DECRETO CON FUERZA DE LEY No 850 DE 1997, QUE FIJA TEXTO REFUNDIDO, COORDINADO Y SISTEMATIZADO DE LA LEY No 15.840, DE 1964, y DEL DFL No 206 DE 1960, SOBRE CONSTRUCCIÓN Y CONSERVACIÓN DE CAMINOS, ACTUAL LEY ORGÁNICA DEL MINSTERIO DE OBRAS PÚBLICAS (EN ADELANTE LOMOP)", EN LOS AUTOS SOBRE RECURSO DE CASACIÓN EN LA FORMA Y apeLACIÓN CARATULADOS "FisCO CON EMPRESA NACIONAL DE TELECOMUNICACIONES S.A.", DE que conoce la Corte de Apelaciones de Santiago, bajo el Rol No 5696-2010 (2012): Tribunal Constitucional Chileno, Rol No 2077-11, 24 de julio de 2012.

REQUERIMIENTO DE INAPLICABILIDAD POR INCONSTITUCIONALIDAD PRESENTADO POR EMPRESA NACIONAL DE TELECOMUNICACIONES S.A. "ENTEL", RESPECTO DEL "INCISO FINAL DEL ARTÍCULO 41 DEL DECRETO CON FUERZA DE LEY No 850 DE 1997, QUE FIJA TEXTO REFUNDIDO, COORDINADO Y SISTEMATIZADO DE LA LEY No 15.840, DE 1964, Y DEL DFL No 206 DE 1960, SOBRE CONSTRUCCIÓN Y CONSERVACIÓN DE CAMINOS, ACTUAL LEY ORGÁNICA DEL MINSTERIO DE OBRAS PÚBLICAS (EN ADELANTE LOMOP)", EN LOS AUTOS SOBRE RECURSO DE CASACIÓN EN LA FORMA Y aPELACIÓN CARATULADOS "FISCO CON EMPRESA NACIONAL DE TELECOMUNICACIONES S.A.", DE que conoce la Corte de Apelaciones de Santiago, bajo el Rol No 4519-2010 (2012): Tribunal Constitucional Chileno, Rol No 2078-11, 24 de julio de 2012.

REQUERIMIENTO DE INAPLICABILIDAD POR INCONSTITUCIONALIDAD PRESENTADO POR EMPRESA NACIONAL DE TELECOMUNICACIONES S.A. "ENTEL", RESPECTO DEL "INCISO FINAL DEL ARTICULO 41 dEL DECRETO CON FUERZA DE LEY No 850 DE 1997, QUE FIJA TEXTO REFUNDIDO, COORDINADO Y SISTEMATIZADO DE LA LEY No 15.840, DE 1964, y DEL DFL No 206 DE 1960, SOBRE CONSTRUCCIÓN Y CONSERVACIÓN DE CAMINOS, ACTUAL LEY ORGÁNICA DEL MINSTERIO DE OBRAS PÚBLICAS (EN ADELANTE LOMOP)", EN LOS AUTOS SOBRE RECURSO DE CASACIÓN EN LA FORMA Y

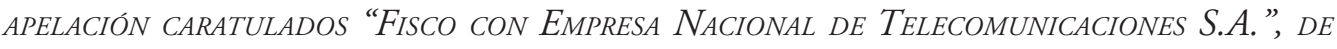
que conoce la Corte de Apelaciones de SANTiago, bajo el Rol No 4277-2010 (2012): Tribunal Constitucional Chileno, Rol No 2079-11, 24 de julio de 2012.

REQUERIMIENTO DE INAPLICABILIDAD POR INCONSTITUCIONALIDAD PRESENTADO POR CONSTRUCTORA SANTA BEATRIZ S.A., RESPECTO DE LOS ARTÍCULOS 29 Y 30 DE LA LEY 17.288, EN LOS AUTOS SOBRE RECURSO DE PROTECCIÓN, CARATULADOS "CONSTRUCTORA SANTA BEATRIZ S.A. CON CONsejo de Monumentos Nacionales y Ministerio de EDUCACión”, DE QUE CONOCE la Corte 
Covarrubias Cuevas, Ignacio / Díaz de Valdés Julia, José Manuel — "La igualdad ante las cargas públicas ...”

de Apelaciones de Santiago, bajo el Rol No 16.593-2014 (2014):Tribunal Constitucional Chileno, Rol No 2299-12, 29 de enero de 2014.

Requerimiento de inconstitucionalidad presentado por un grupo de Diputados, respecto de parte de las glosas que indica correspondiente al proyecto de Ley de Presupuesto del Sector Público, para el año 2016, correspondiente al boletín No 10.300-2015 (2015): Tribunal Constitucional Chileno, Rol No 2935-15, 21 de diciembre de 2015. 